\title{
Stratospheric background aerosol and polar cloud observations by laser backscattersonde within the framework of the European project "Stratospheric Regular Sounding"
}

\author{
A. Adriani ${ }^{1}$, F. Cairo ${ }^{1}$, L. Pulvirenti ${ }^{1}$, F. Cardillo ${ }^{1}$, M. Viterbini ${ }^{1}$, G. Di Donfrancesco ${ }^{2}$, J. P. Pommereau $^{3}$ \\ ${ }^{1}$ CNR - Istituto di Fisica dell'Atmosfera, Via del Fosso del Cavaliere 100, 00133 - Roma, Italy \\ E-mail: adriani@atmos.fa.rm.cnr.it \\ ${ }^{2}$ ENEA Casaccia, Dip. Ambiente, Via Anguillarese 301, 00060 - S. Maria di Galeria, RM, Italy \\ ${ }^{3}$ CNRS - Service d'Aeronomie - BP 3, 91371 Verrieres le Buisson CEDEX, France
}

Received: 2 December 1998 / Revised: 19 May 1999 / Accepted: 16 June 1999

\begin{abstract}
The Stratospheric Regular Sounding project was planned to measure regularly the vertical profiles of several tracers like ozone, water vapor, $\mathrm{NO}_{\mathrm{x}}, \mathrm{ClO}_{\mathrm{x}}$ and $\mathrm{BrO}_{\mathrm{x}}$ radicals, aerosol, pressure and temperature, at three latitudes, to discriminate between the transport and photochemical terms which control their distribution. As part of this project, the "Istituto di Fisica dell'Atmosfera" launched nine laser backscattersondes (LABS) on board stratospheric balloons to make observations of background aerosol and PSCs. LABS was launched with an optical particle counter operated by the University of Wyoming. Observations have been performed in the arctic, mid-latitudes and tropical regions in different seasons. Polar stratospheric clouds have been observed in areas inside and outside the polar vortex edge. A background aerosol was observed both in mid-latitudes and in arctic regions with a backscattering ratio of 1.2 at $692 \mathrm{~nm}$. Very stratified aerosol layers, possibly transported into the lower stratosphere by deep convective systems, have been observed in the lower stratosphere between 20 and $29 \mathrm{~km}$ in the tropics in the Southern Hemisphere.
\end{abstract}

Key words. Atmospheric composition and structure (aerosols and particles; middle atmosphere composition and chemistry; instruments and techniques)

\section{Introduction}

The long-term ozone loss at mid and high latitudes in the stratosphere depends on dynamical and chemical factors. Ozone is transported from the tropics where it originates. Later gas phase and heterogeneous processes involving radicals $\left(\mathrm{HO}_{\mathrm{x}}, \mathrm{NO}_{\mathrm{x}}, \mathrm{ClO}_{\mathrm{x}}, \mathrm{BrO}_{\mathrm{x}}\right)$ and particles

Correspondence to: A. Adriani (background aerosol and PSCs) take place, controlling further evolution of its concentration. The sources of these radicals are long-lived natural or man-made gases emitted at the surface of the Earth and transported upward across the troposphere in a few weeks, then move slowly into the stratosphere over a few years. The vertical distribution of the concentration of the radicals and ozone is thus the result of a combination of transport and chemical processes experienced by the air mass along its trajectory. In such scenarios, important dynamical parameters are the time constants of transport across the tropopause at the equator and across the sub-tropical jet and the edge of the polar vortex from the tropopause up to $30 \mathrm{~km}$. From the microphysical and photochemical points of view, the de-hydration mechanisms at the pole and at the equator, the size distribution of aerosol, the heterogeneous conversion of $\mathrm{NO}_{\mathrm{x}}$ into aerosol or PSCs, the global distribution of $\mathrm{BrO}$ and the average ozone reduction and denitrification in the Arctic vortex in winter play key roles.

The Stratospheric Regular Soundings (SRS) project was funded by the European Commission for the years 1996-1997. The project objective was the regular measurement of the vertical profiles of several tracers such as ozone, water vapor, source gases $\left(\mathrm{N}_{2} \mathrm{O}, \mathrm{CFCs}, \mathrm{CH}_{4}\right)$, radicals $\left(\mathrm{NO}_{2}, \mathrm{OClO}, \mathrm{BrO}\right)$, background and volcanic aerosol, PSCs, pressure and temperature at three latitudes and from the tropopause up to $30 \mathrm{~km}$, to discriminate between the transport and photochemical terms which control their distribution. Another objective was to investigate the anticipated time constants of transport by correlation between tracers of different atmospheric history, and to simulate the results with 3D and Langrangian photochemical models to differentiate transport and chemical terms. The vertical profiles of the species were measured by a combination of light-weight instruments carried by relatively small balloons with different payloads. The instruments included the SAOZ uv-visible spectrometers (Pommereau et al., 1994) of the Service d'Aéronomie du CNRS, France, for $\mathrm{O}_{3}, \mathrm{NO}_{2}$, $\mathrm{OClO}, \mathrm{BrO}$ and optical extinction; the DESCARTES 
sampler (Pyle et al., 1994) of the University of Cambridge, United Kingdom, optimized for CCF 11, but also used for measuring profiles of $\mathrm{CFC} 113, \mathrm{CCl}_{4}$ and $\mathrm{CH}_{3} \mathrm{CCl}_{3}$; the Lyman-alpha hygrometer (Katthatov et al., 1994) of the Central Aerological Observatory, Russia, for in-situ water vapor, the Optical Particle Counter (Hofmann et al., 1989; Deshler et al., 1994) of the University of Wyoming, USA, and the laser backscattersonde (Adriani et al., 1998, 1999) of the Istituto di Fisica dell'Atmosfera del Consiglio Nazionale delle Ricerche, Italy, for optical, concentration and size measurements on stratospheric particulate matter. A total of 31 flights with different payloads were made from different sites in Europe and Brazil. Among these, nine flights were performed from Andoya $\left(69^{\circ} \mathrm{N}\right.$, Norway), Gap Tallard $\left(44^{\circ} \mathrm{N}\right.$, France), Laramie $\left(42^{\circ} \mathrm{N}\right.$, USA), and Bauru $\left(22^{\circ} \mathrm{S}\right.$, Brazil) with payloads equipped with optical particle counters and laser backscattersondes for aerosol measurements.

A number of papers describing some of the SRS results, except for those described here, have been published by Nilsson et al. (1997), Preston et al. (1997), Deniel et al. (1998), Danis et al. (1998), Lambert et al. (1999), Pommereau et al. (1998), and Pundt et al. (1998).

We focus our presentation on the observations made by laser backscattersondes. We dedicate a section to the description of the instrument (characteristics and products) and another to the observations made over the two years of the project.

\section{The laser backscattersonde}

Laser backscattersondes (LABS), Fig. 1, have been used in order to perform optical measurements on the stratospheric background aerosol and PSCs. LABS has been routinely flown along with optical particle counters (OPC) from the University of Wyoming.

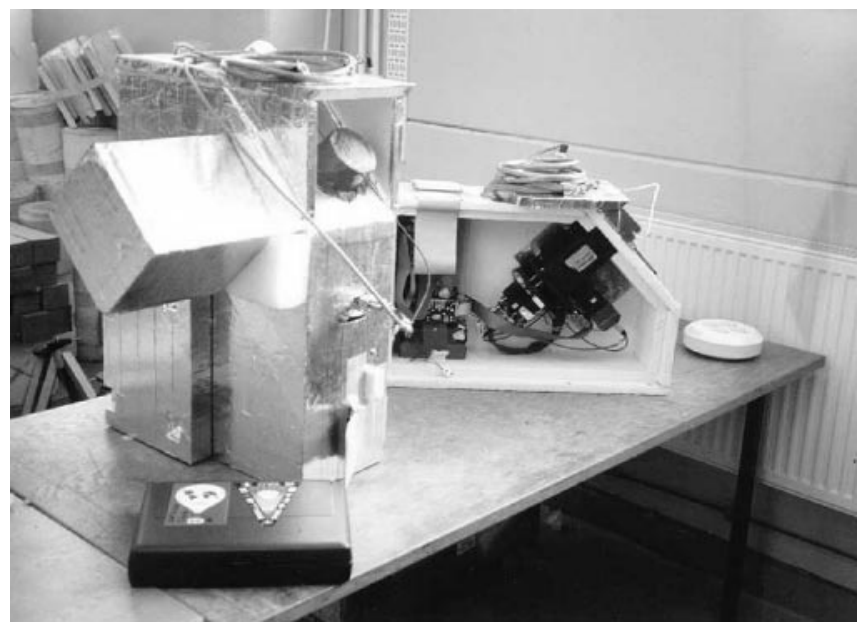

Fig. 1. Two of the laser backscattersondes used in the SRS project. One of the II type (open, on right): 1 wavelength/2 receiving channel; the modified version of the same type (closed, on left): 2 wavelengths/3 receiving channels. The open one shows the optical head on the right and electronics batteries on the left. Box size is about $61 \times 22 \times 50 \mathrm{~cm}$
The basic instrument had two detection channels and can measure laser light backscattered from atmosphere in the close field. It uses laser diodes as a light source and the emission is polarized. A version of the instrument, with two lasers at 692 and $830 \mathrm{~nm}$, was used for background aerosol measurements. A second version of LABS with one single laser wavelength $(692 \mathrm{~nm})$ but able to make backscattering measurements on parallel and cross polarization was preferred for observations in the presence of PSCs. One more laser and one more receiving channel at $830 \mathrm{~nm}$ were developed on an instrument of the second type. Such a modified LABS instrument was used only once during a strong PSC event because it was lost after the flight because of a malfunction in the balloon separation system. Its optical layout is sketched in Fig. 2. The main functional characteristics of the instruments are summarized in Table 1.

The lasers emitted powers were about 20 and $15 \mathrm{~mW}$ respectively. The instrument actually performs an in situ

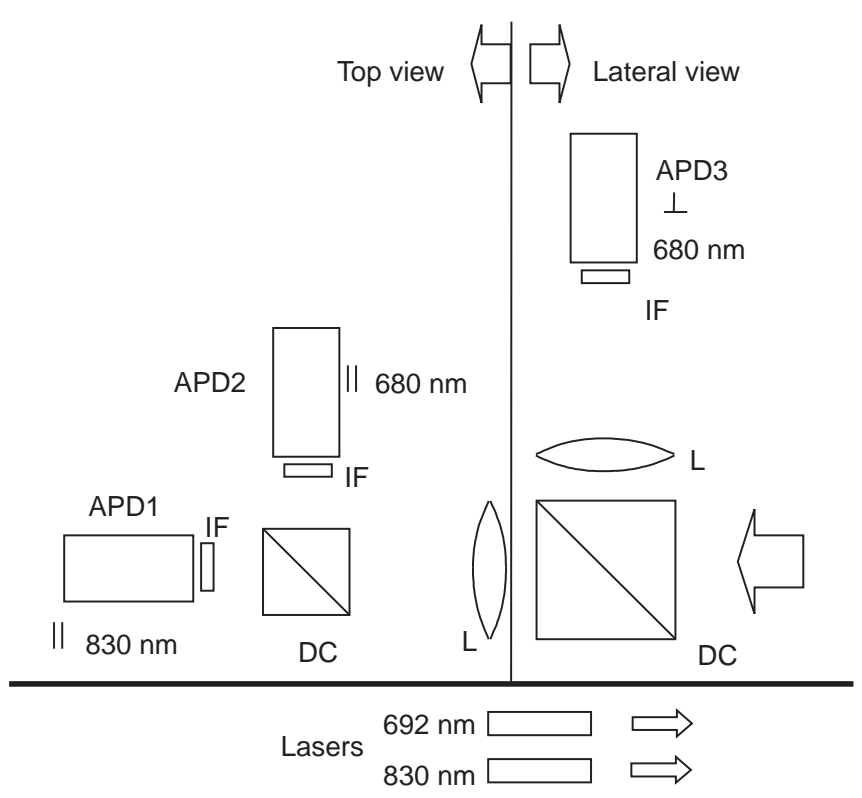

Temperature and Laser monitors and pressure sensors optical detectors

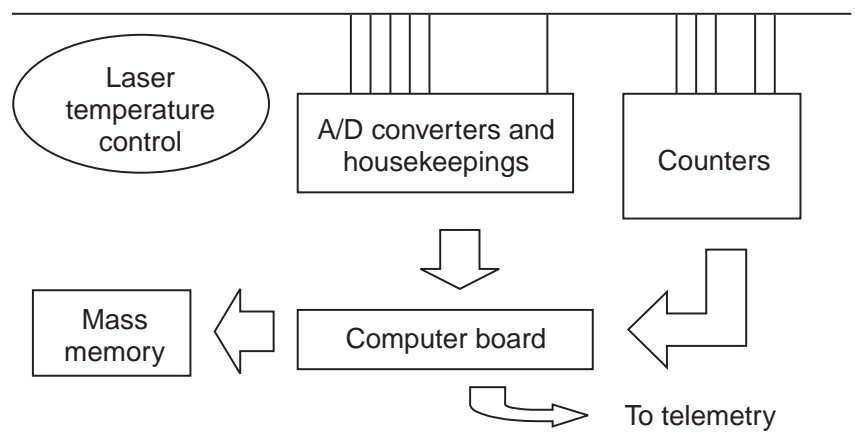

Fig. 2. Layout of one of the LABS used during the SRS project. Note that the optical part is split into two views. $A P D$, avalanche photodiodes; $D C$, dicroics for polarization and for wavelength separation; $I F$, interference filters; L, lens 
Table 1. Typology of the LABS sondes used in SRS project

\begin{tabular}{llll}
\hline Type of instrument & No. of $\lambda$ & Depolarization & Primary use \\
\hline I & 2 & No & Background \\
& & aerosol \\
II & 1 & Yes & PSC \\
Improved II & 2 & Yes & PSC \\
\hline
\end{tabular}

measurement by sounding the atmosphere at close range between 5 and $40 \mathrm{~m}$. The backscattered signal was acquired for $1 \mathrm{~s}$ in a $2 \mathrm{~s}$ duty cycle, the vertical resolution, determined by the balloon ascent speed, was $10 \mathrm{~m}$ on average. The detection channels used avalanche photodiodes working in a photon counting mode. The sondes had on-board computers for data acquisition and the data were both stored in mass memory and sent through the OPC's telemetry to the ground station.

LABS is able to measure some optical parameters of the atmospheric particles (Adriani et al., 1998a, b). The primary parameters retrieved from the measurements are backscattering ratio at any used wavelength and volume depolarization. In order to produce the backscattering ratio, the pressure and the temperature of the external environment have to be used. Such data were directly measured in flight by OPC. On this basis, the signal expected from the molecular atmosphere and the backscattering ratio $R$ could be calculated. $R$ is equal to $\left(\beta_{p}+\beta_{m}\right) / \beta_{m}$, where $\beta_{p}$ and $\beta_{m}$ are the volume backscattering cross sections for particles and molecules, respectively. $\beta_{p}$ is a function of the particle sizes distribution and concentration, the refractive index and the wavelength. At a given wavelength, $\beta_{m}$ is proportional to the molecular air density. Essentially, $R$ is a measurement of how much the signal backscattered from the particles exceeds the molecular one. On this basis it is possible to retrieve the vertical structure of the cloud and some other optical parameters. $\beta_{p}$ is proportional to the optical extinction of the cloud and to the average surface area of the particles. The particle extinction coefficient, $E_{p}$, can be retrieved by $E_{p}=C^{*} \beta_{m}^{*}(R-1)$ where the parameter $C$ is dependent on the kind of particles involved in the measurement. Values of $C$ can be found in the literature (Collis and Russell, 1976; Jaeger et al., $1991,1995) . R=1$ means that no particles are present in the air volume sounded.
Depolarization measurements were used in PSCs observations to distinguish between liquid and/or solid particles because the former ones, since they are spherical, do not depolarize the backscattered light. According to the most recent theories on PSCs (Peter, 1997), they may be formed by liquid and/or solid particles depending on the air-mass temperature, their thermal history and a proper abundance of their constituents in gas phase to condense. Liquid particles may be supercooled ternary solution droplets (LTA) $\mathrm{H}_{2} \mathrm{O} / \mathrm{H}_{2} \mathrm{SO}_{4} / \mathrm{HNO}_{3}$ and solid particles sulfuric acid tetra-hydrated (SAT) crystals or, if they experience temperatures lower than about $195 \mathrm{~K}$, nitric acid trihydrated (NAT) or, at even lower temperatures, possibly ice.

Knowledge of the thermodynamic phase of the particles can help in studies of polar stratospheric clouds which have a key role in ozone depletion in polar stratospheres. Indeed, PSCs formation processes and their other characteristics are not yet well known. The volume depolarization, $D$, can be computed by the formula $D=k\left(S_{c} / S_{p}\right)$ where $S_{p}$ and $S_{c}$ are respectively the polarized and the cross-polarized signals at a given wavelength measured by the sonde. The calibration constant, $k$, is calculated making the depolarization equal to 1.4 where no particles are present. Such a value is the one estimated for the pure molecular atmosphere (Young, 1980; Cohen and Low, 1969).

\section{Observations}

Nine launches of LABS have been carried out in the frame of the SRS project. They are listed in Table 2. Four launches were performed at arctic latitudes, three at mid-latitudes and two in the Southern Hemisphere near the Tropic of Capricorn latitude. The arctic flights were performed both outside and inside the vortex with the main goal of investigating polar stratospheric clouds. Aerosol background measurements were performed at the same time. The stratospheric aerosol background was also measured at mid-latitudes and at the tropics. A brief description of all the observations of stratospheric particulate matter during SRS is given hereafter. The most interesting cases illustrated are now under more detailed study.
Table 2. List of the LABS observations

\begin{tabular}{|c|c|c|}
\hline Date & Site & Comments \\
\hline $23-1-96$ & Andoya, Norway & $\begin{array}{l}\text { Successful. External side of the } \\
\text { polar vortex border. }\end{array}$ \\
\hline $6-2-96$ & Andoya, Norway & Successful. Inside the polar vortex. \\
\hline $26-6-96$ & Gap, France & Successful. No particle data from OPC \\
\hline $11-11-96$ & Laramie, USA & Successful \\
\hline $14-1-97$ & Andoya, Norway & $\begin{array}{l}\text { Successful. No particle data from OPC. } \\
\text { Inside the polar vortex. }\end{array}$ \\
\hline $19-1-97$ & Andoya, Norway & $\begin{array}{l}\text { LABS failure: payload crash during } \\
\text { take-off in strong winds }\end{array}$ \\
\hline $27-6-97$ & Gap, France & Noisy signal \\
\hline $23-11-97$ & Bauru, Brazil & Telemetry failure at $20 \mathrm{~km}$ \\
\hline $26-11-97$ & Bauru, Brazil & Successful \\
\hline
\end{tabular}




\subsection{Arctic measurements}

Observations in the arctic region were performed from Andoya during both 1996 and 1997 winters. Four launches took place as listed in Table 2. The two 1996 flights, on 23 January and 6 February, were fully successful. A successful flight was performed also during 1997, on 14 January. PSCs were detected during all three flights. All clouds are reported in the volume-depolarization/backscattering-ratio scatter plot in Fig. 3. The observed PSCs can be classified as Ia, probably NAT or SAT, (6 February, 1996) and Ib, probably LTA, (23 January, 1996 and 14 January, 1997) according to the classification suggested by Browell et al. (1990) based on depolarization and backscattering ratio measurements. In the picture, the 23 January cloud shows a tail going toward type II PSC (ice cloud) due to a depolarizing core observed inside the cloud itself. On the other hand, the top layer of the same cloud can be classified as Ia PSC type.

The 23 January, 1996, observation represents a quite unique and interesting case study for the contemporary observations of the same event by laser backscattersonde, optical particle counter, condensation nuclei counter and ground-based ALOMAR lidars at Andoya. The latter were the Norwegian ozone lidar and the French rayleigh lidar. LABS and lidars provided optical measurements of the same cloud at 308, 353, 532, 692, 830 and $1064 \mathrm{~nm}$. So far, most of the scientific work has been focused on this case study (Adriani et al., 1998; Deshler et al., 1998, 1999; Fierli et al., 1998). According to correlated information, the cloud was observed on the external side of the polar vortex edge. The PSC, shown in Fig. 4, was observed between 20 and $26 \mathrm{~km}$ altitude. It was mostly liquid with a core containing solid particles at 23-24 km; solid particles were also detected at the top of the cloud at $26-27 \mathrm{~km}$. The temperature was close to ice frost point $(\approx 185 \mathrm{~K})$ at its minimum inside the cloud. The condensation temper-

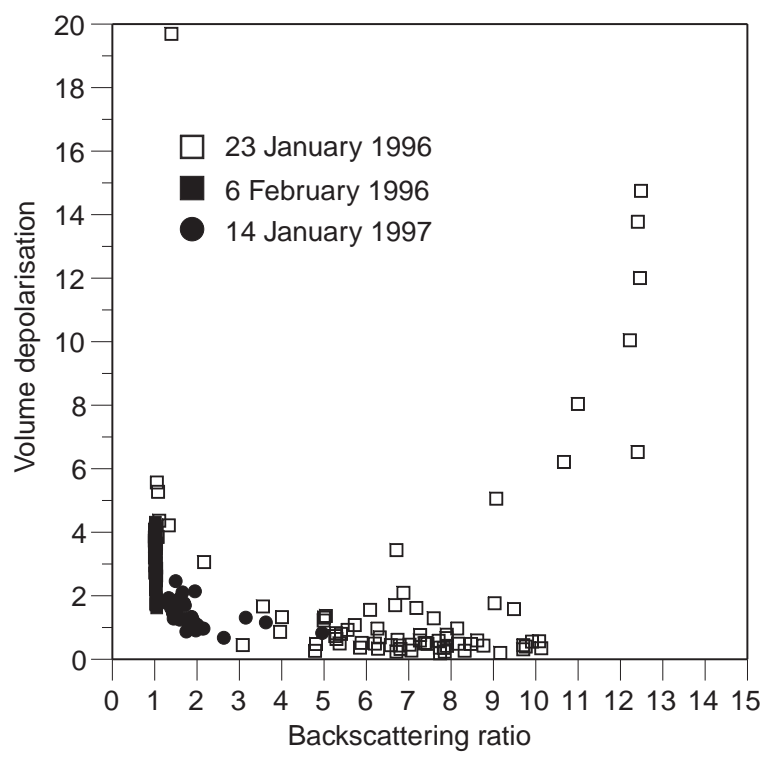

Fig. 3. Volume depolarization versus backscattering ratio scatter plot for PSC measurements during SRS at $692 \mathrm{~nm}$ ature for ice, NAT (Hanson and Mauerberger, 1988) and LTA (Carslaw et al., 1995) formation are reported in Fig. 4 on the temperature plot. Values of 4.5 ppmv $\mathrm{H}_{2} \mathrm{O}$ mixing ratio at the cloud levels were measured on the same day at Sodankyla in northern Finland by a frost point hygrometer. A value of $10 \mathrm{ppbv}$ has been used for the $\mathrm{HNO}_{3}$ mixing ratio. Unfortunately, the Lyman-alpha hygrometer was never able to fly in conjuction with LABS flights. Backtrajectories show that the airmass experienced a cooling rate of $16 \mathrm{~K} /$ day during the previous $36 \mathrm{~h}$. The particle counters showed that all particles in the airmass grew to sizes larger $0.3 \mu \mathrm{m}$ in diameters (T. Deshler, private communication). Balloon and lidar measurements have been correlated. By combining optical particle counter and laser backscattersonde measurements, an index of refraction of 1.47 in the liquid part of the cloud was derived (Deshler et al., 1999).

PSCs were also observed during the other two arctic LABS flights. On 6 February, Andoya was just inside the polar vortex border and a solid PSC was observed at 25$27.5 \mathrm{~km}$ (Fig. 5). Temperatures were relatively high at those altitudes ranging between 200 and $210 \mathrm{~K}$. LABS measurements showed a very low backscattering ratio $(1.02-1.03)$ along with a volume depolarization up to 3$4 \%$. Contemporaneously, at the same altitude, the optical particle counter showed the presence of a cloud composed by small particles (T. Deshler, personal communication). Since the observed temperature was relatively high for nitric acid tri-hydrated (NAT) cloud particles, it is possible that sulphuric acid tetrahydrate (SAT) particles, very small in size and solid then depolarising, were observed in this case. Evidence of observations of solid sulfate aerosols has been reported in the literature by other authors (Gobbi and Adriani, 1993; Toon et al., 1993; Larsen et al., 1995) but this is the first in situ observation where optical and particle concentration measurements were performed. Backtrajectory calculations show that the air mass in which the cloud was observed passed over south Greenland 18$20 \mathrm{~h}$ before reaching the Scandinavian peninsula. Temperature and wind profiles, as measured by meteorological sondes in that area, clearly show a local cyclonic activity associated with gravity wave perturbations propagating to high altitude. The formation of SAT particles could be associated with the formation of solid particles inside the lee waves above Greenland. At the moment, this case is under further investigation. During the same measurement a backscattering ratio from the stratospheric aerosol background of about 1.15-1.2 was observed from the tropopause (about $11 \mathrm{~km}$ ) to $17 \mathrm{~km}$. During the 1997 arctic campaign, another PSC (liquid, i.e., no depolarizing) was observed at altitudes of 25 $27 \mathrm{~km}$ near Andoya on 14 January, 1997, (Fig. 6). The temperature at that altitude range was lower than $186 \mathrm{~K}$ with a minimum reaching about $183 \mathrm{~K}$. There, the temperature was about $2 \mathrm{~K}$ higher than the ice frost point at that altitude and the cloud was probably formed by liquid ternary aerosol formed by $\mathrm{HNO}_{3} / \mathrm{H}_{2} \mathrm{SO}_{4} / \mathrm{H}_{2} \mathrm{O}$ solution. The condensation temperature versus the altitude for NAT, LTA and ice are plotted in Fig. 6 along with the temperature profile. Unfortunately, as 


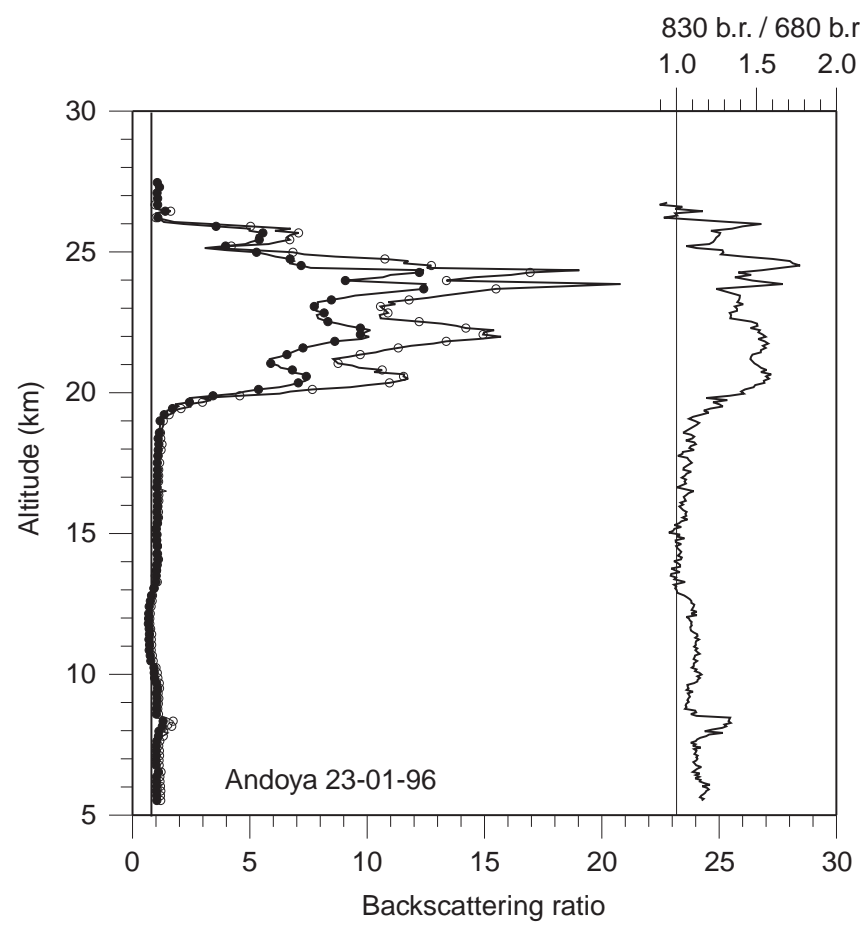

Fig. 4. 23 January, 1996. Left: backscattering ratio at $692 \mathrm{~nm}$ (black dots) and $830 \mathrm{~nm}$ (open circles) by LABS and color index (solid line) as ratio between two backscattering ratios. Right: volume depolarization

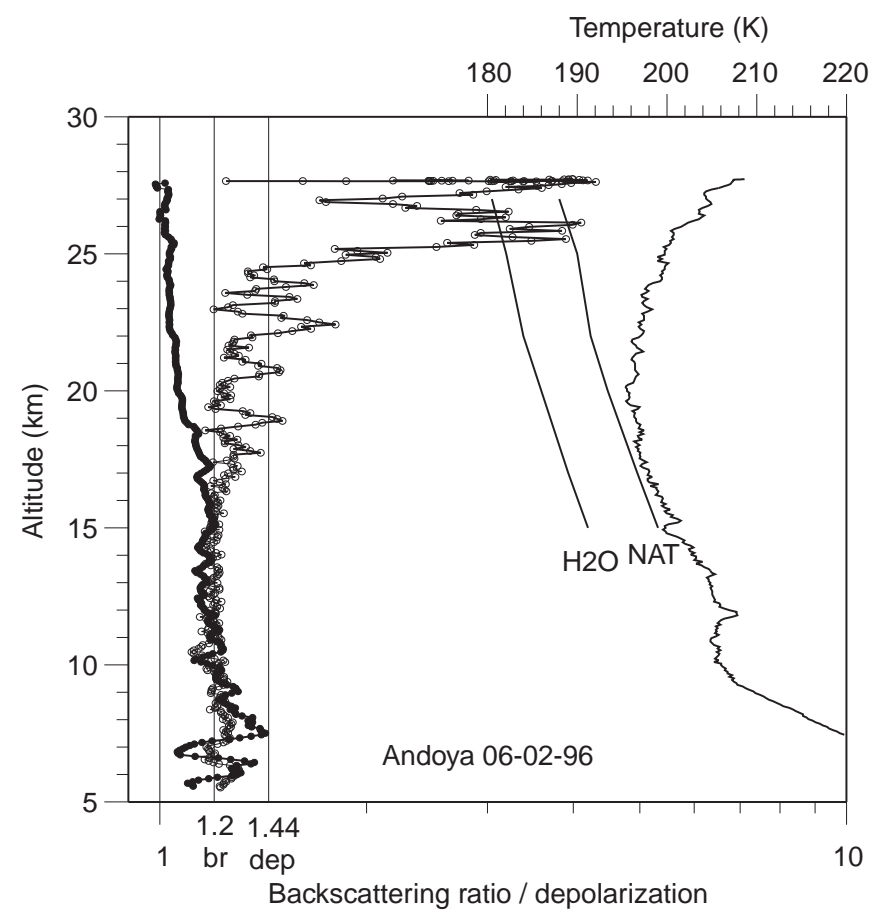

Fig. 5. Polar stratospheric cloud observed over Andoya, Norway, on 6 February, 1996. Backscattering ratio at $692 \mathrm{~nm}$ (black dots) and volume depolarisation at the same wavelength (open circles) and temperature; condensation temperature are also reported as function of the altitude for ice and NAT calculated for 4.5 ppmv $\mathrm{H}_{2} \mathrm{O}$ and 10 ppbv $\mathrm{HNO}_{3}$ mixing ratios

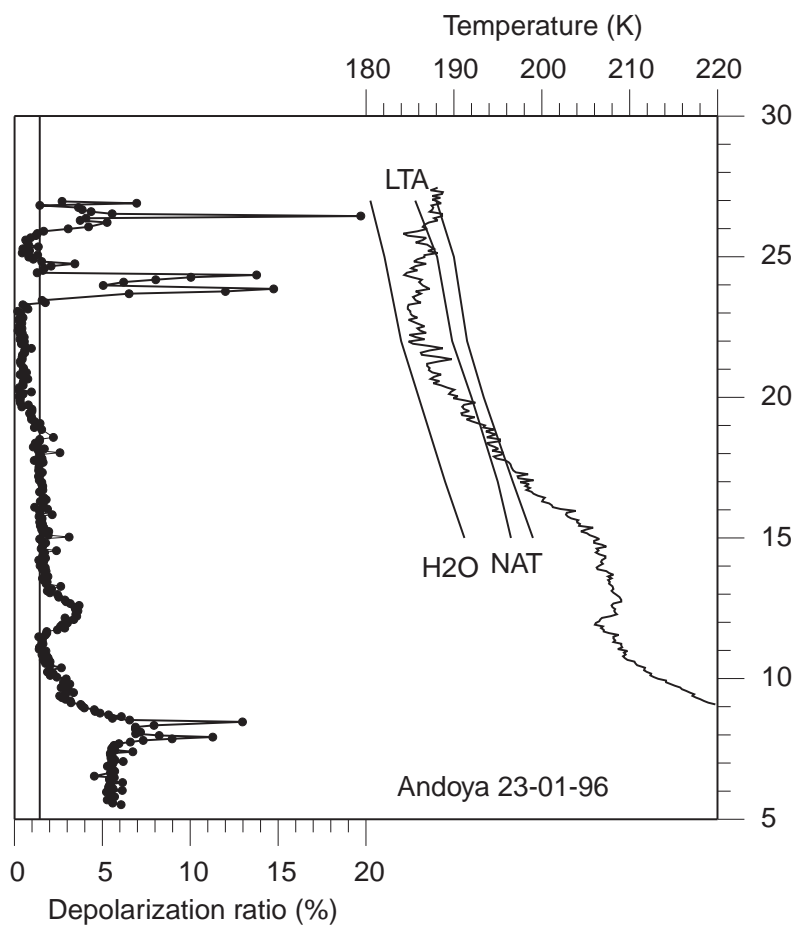

at $692 \mathrm{~nm}$ (black dots) and temperature; condensation temperatures are also shown as a function of the ice altitude. LTA and NAT calculated for 4.5 ppmv $\mathrm{H}_{2} \mathrm{O}$ and 10 ppbv $\mathrm{HNO}_{3}$ mixing ratios

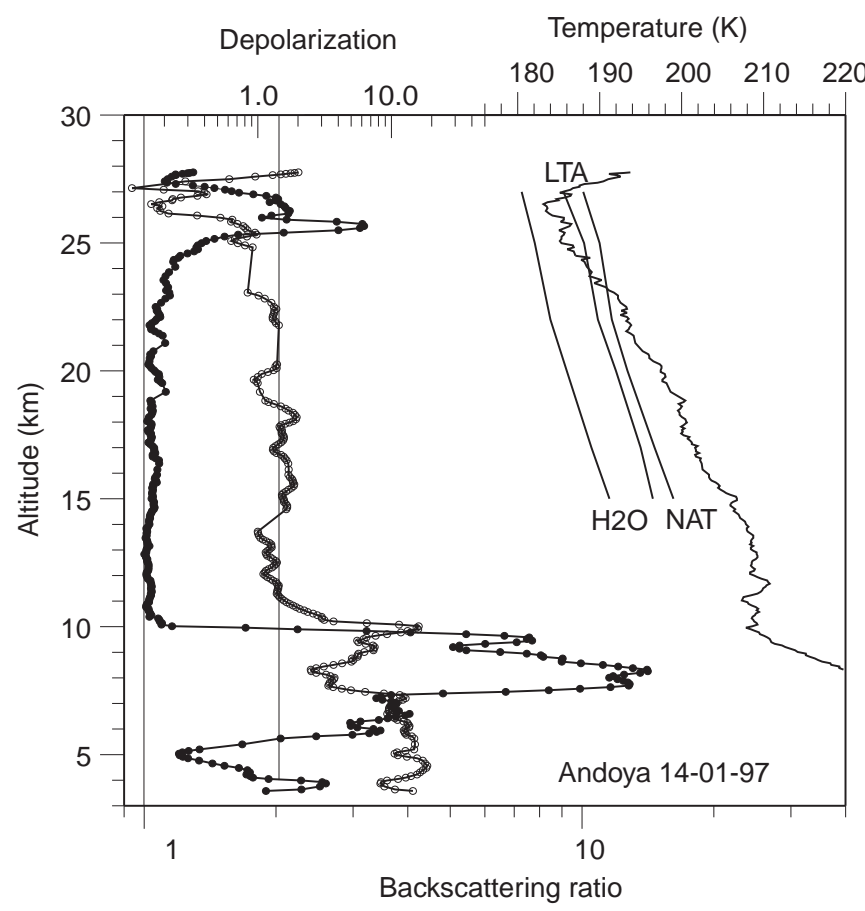

Fig. 6. Polar stratospheric cloud observed over Andoya, Norway, on 14 January, 1997. Backscattering ratio at $692 \mathrm{~nm}$ (black dots) and volume depolarisation at the same wavelength (open circles) and temperature; condensation temperature are also reported as function of the altitude for ice, LTA and NAT calculated for 4.5 ppmv $\mathrm{H}_{2} \mathrm{O}$ and 10 ppbv $\mathrm{HNO}_{3}$ mixing ratios 
previously mentioned, no particle measurements were taken during this flight so that no comparison between optical data and particle size distribution is possible.

\subsection{Mid-latitude and tropical measurements}

During the SRS campaigns at mid-latitudes, good measurements were taken only in 1996 (Fig. 7). They are from Gap Tallard in southern France on 26 June and from Laramie, Wyoming, USA, on 11 November. Another flight from Gap Tallard was attempted during

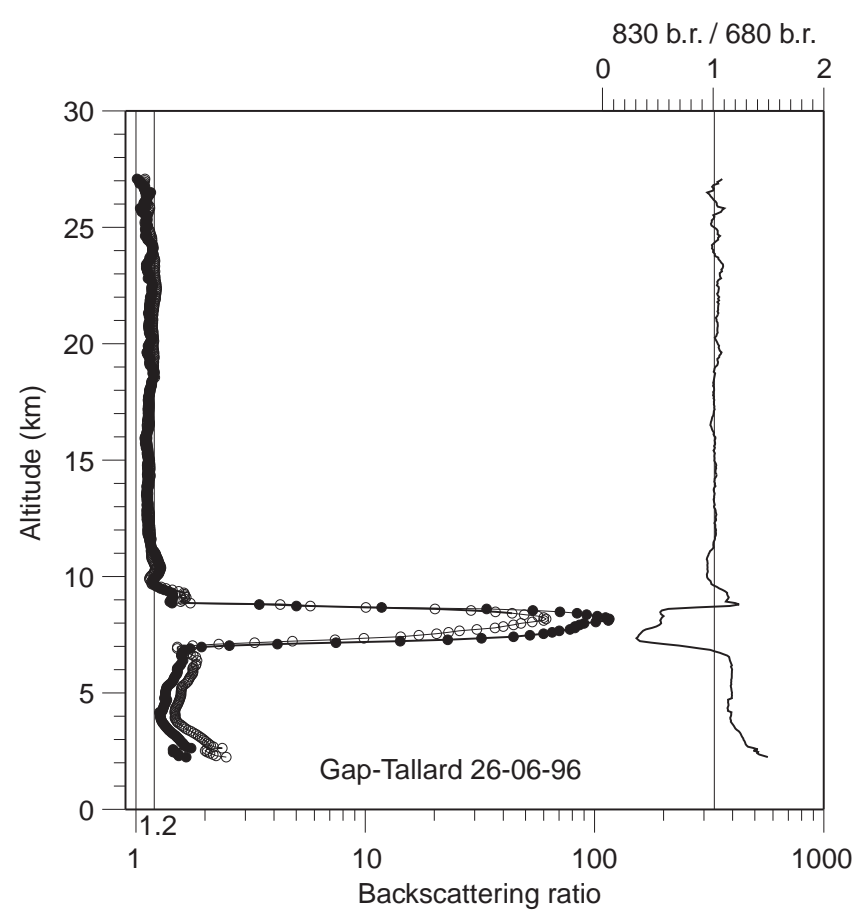

Temperature $(\mathrm{K})$

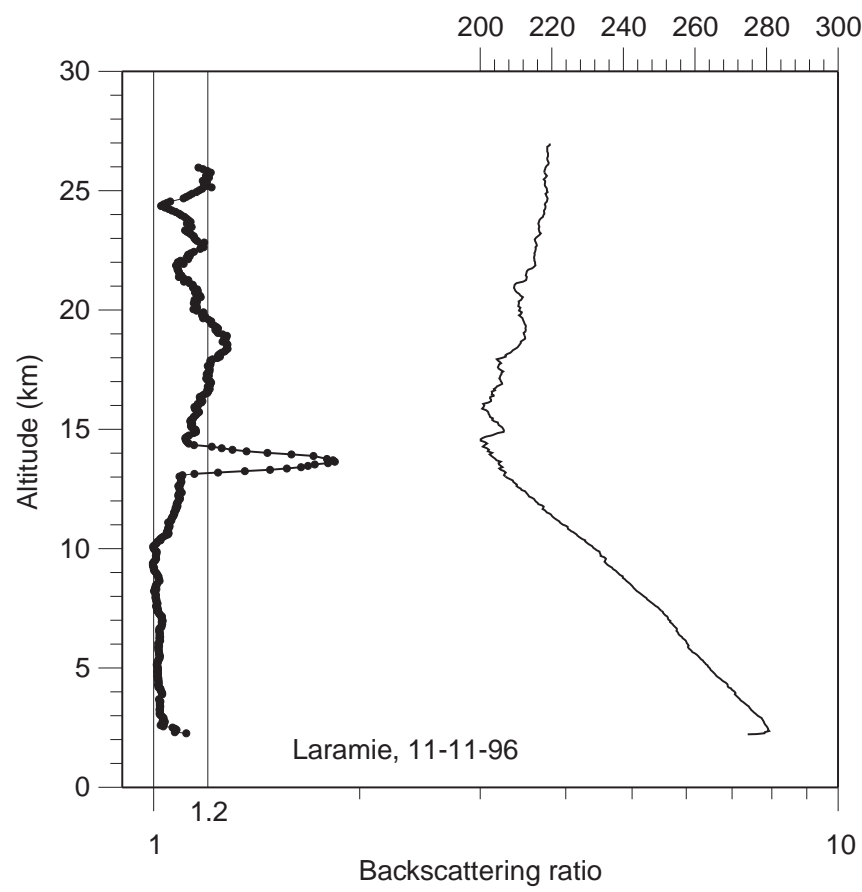

1997 but, some electronic problem made the signal very noisy and, thus those measurements are not reliable for quantitative measurements. All 1996 measurements show cirrus clouds just below the tropopause. The temperature profiles show tropopause levels very different from one case to the other. On 26 June, the tropopause above Gap was at about $10 \mathrm{~km}$ and, on 11 November, there was a double tropopause at approximately 14.8 and $16 \mathrm{~km}$ above Laramie with a temperature of $200 \mathrm{~K}$.

The backscattering ratio was around 1.2 in both cases with small differences between wavelengths (Gap mea-

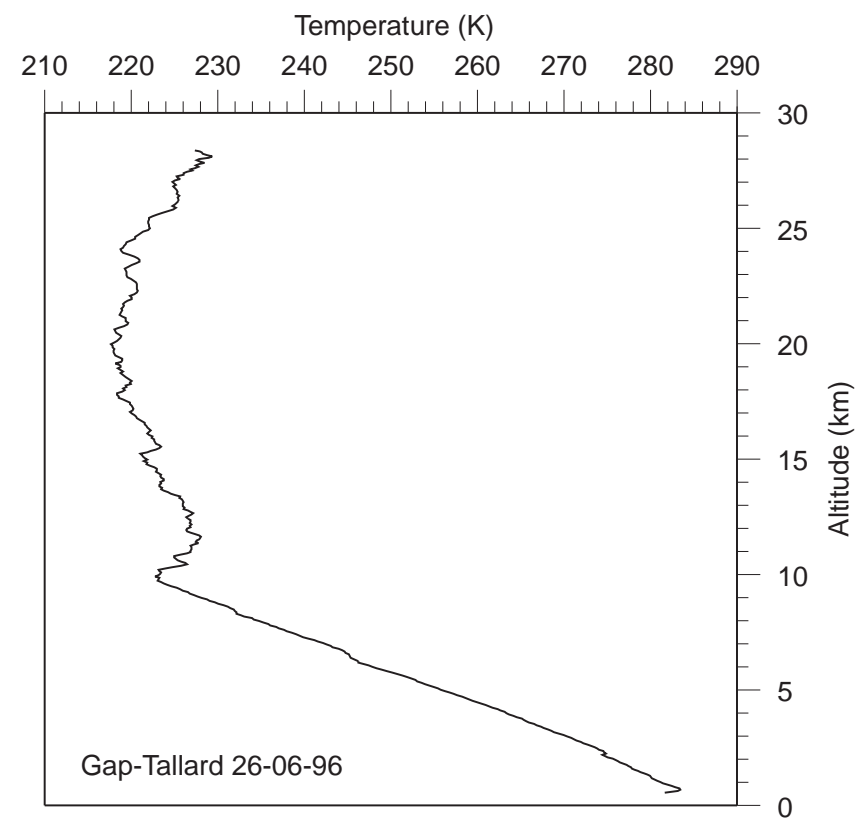

Fig. 7. Mid-latitude measurements taken on 26 June 1996 at GapTallard, Southern France and on 11 November 1996 at Laramie, Wyoming, USA. Upper left panel: backscattering ratio at 692 (black dots) and 830 (open circles) nm, and colour index (solid line) as ratio between the two backscattering ratios. Upper right panel: temperature. Lower panel: Backscattering ratio at 692 (black dots) and temperature (solid line) 
surement) and altitudes. In both cases the aerosol particles extended to high altitude levels. During the 26 June flight, LABS observed the presence of particles up to $27 \mathrm{~km}$ (no particle measurements are available from the OPC). On 11 November the optical particle counter measured particles up to $31-32 \mathrm{~km}$. In that case the LABS data were quite close to the instrumental signal background at $27 \mathrm{~km}$ and the data above $26 \mathrm{~km}$ have been removed from the plot because they lost significance for low signal-to-noise ratio.

Two launches were performed at Bauru, Brazil, on 23 and 26 November, 1997, (Fig. 8). During the 23 November flight, the telemetry started malfunctioning at the tropopause level $(17.5 \mathrm{~km})$ and stopped working completely at $20-21 \mathrm{~km}$ because of battery problems. Stratified cloud was observed in the troposphere between $10 \mathrm{~km}$ and the tropopause at about $16-17 \mathrm{~km}$. The temperature at the tropopause was $190 \mathrm{~K}$.

A similar situation was present in the troposphere three days later during the second flight. On 26 November the tropopause was at $17.8 \mathrm{~km}$ and its temperature was still $190 \mathrm{~K}$. Various cloud layers were present in the troposphere between 3 and $18 \mathrm{~km}$. In the lower stratosphere, between 20 and $29 \mathrm{~km}$, a layered aerosol structure was observed. The temperature at that interval of altitudes increased from 204 to $224 \mathrm{~K}$. Those aerosols were probably injected in the lower stratosphere at the intertropical convergence zone and advected above the observation site. Nine-days of backtrajectories based on the ECMWF data base have been calculated in order to investigate the origin of those layered aerosol clouds. The backtrajectories have been computed at many isentropic levels between 400 and $720 \mathrm{~K}$ and the more

Temperature $(\mathrm{K})$

180200220240260280300

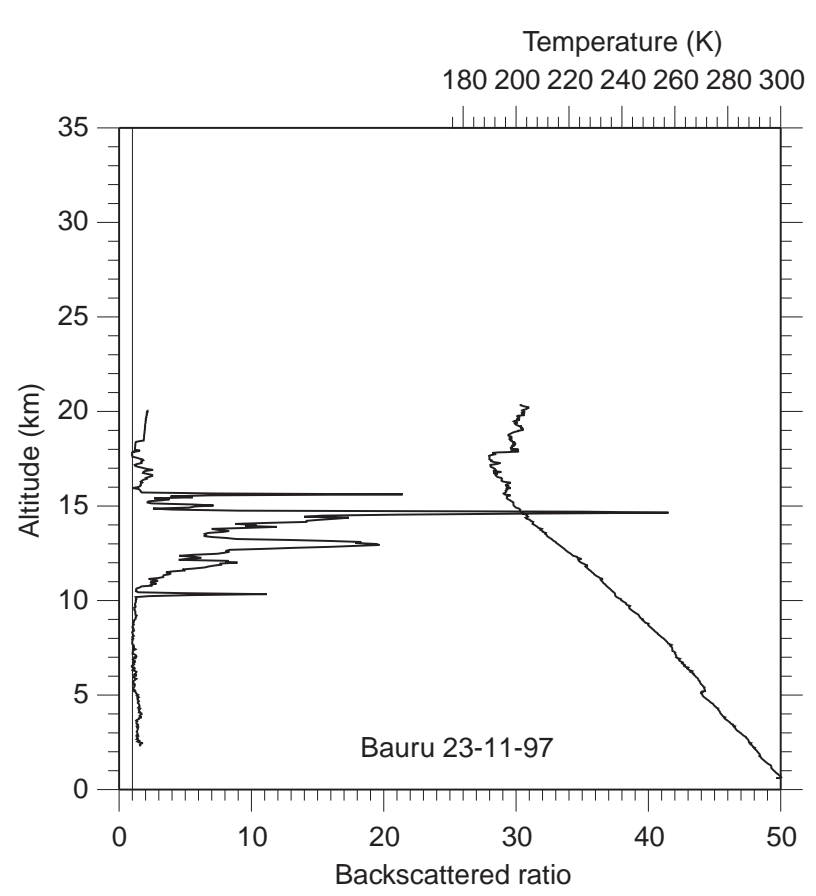

significant layers are shown in Fig. 8. The stratification observed in the aerosol profile suggests that the injection of this aerosol was quite recent since not much vertical homogeneity was observed. Air mass trajectories from the east show two different histories for the two portions of the atmosphere between 19 and $24 \mathrm{~km}(450-600 \mathrm{~K})$ and between 24 and $28 \mathrm{~km}(600-720 \mathrm{~K})$. However, they show that both layers passed over central Africa about 9 days earlier, before moving above South America, from southern and northern Zaire respectively. The aerosol layer could easily be injected by a deep convective system which pierced the lowest part of the troposphere and transported the particles up into the lower stratosphere. This case is presently under further investigation. However, the issue of the aerosol budget in the intertropical lower stratosphere has a key role both in the radiation budget of the planet and in the transport of aerosol toward the polar regions. So far, the knowledge in this field is still poor. Questions such as how important is the role of the convective systems in transporting particulate matter from the lower troposphere to the upper troposphere and into the lower stratosphere or how much of the material is directly transported from the boundary layer and how much is formed in situ are still not completely answered. More extended and systematic investigations into the troposphere-stratosphere exchanges in the intertropical region are certainly needed.

\section{Conclusions}

The goal of the Stratospheric Regular Sounding projects was the monitoring of the stratosphere using various

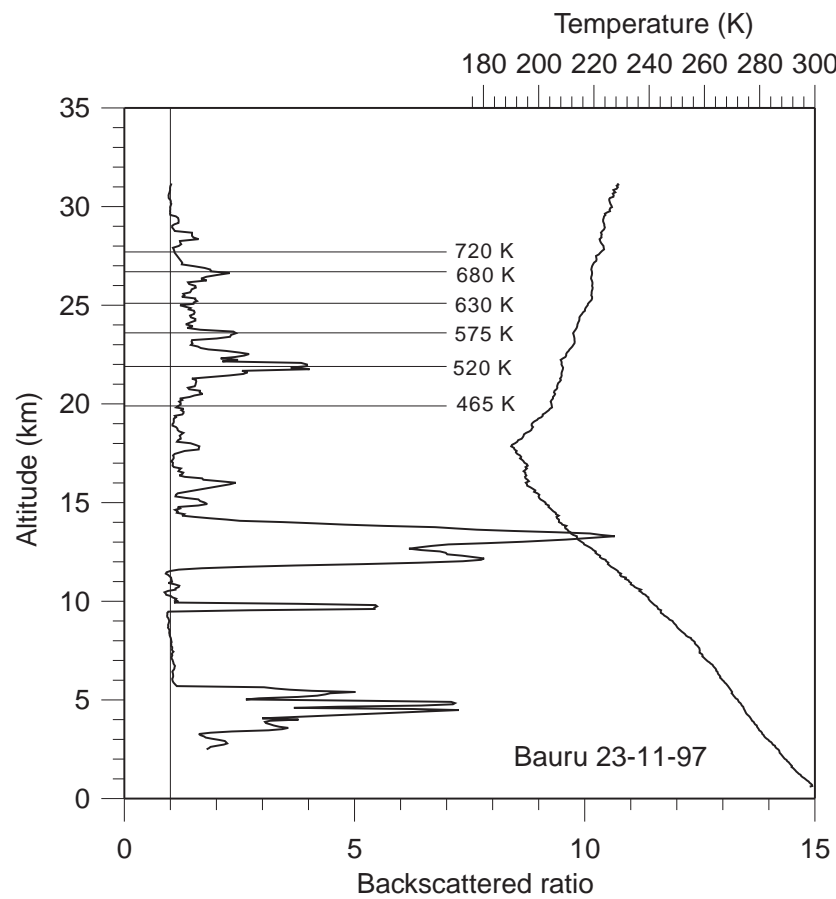

Fig. 8. Tropical measurements at Bauru, Brazil. Backscattering ratio and temperature profiles as measured on 23 and 26 November 1997. Backscattering ratios are measured at $692 \mathrm{~nm}$. On the right panel, the most significant insentropics levels at which the backtrajectories have been calculated 
instruments flown by small balloons at different latitudes and seasons in low-volcanic aerosol conditions. In fact, the last large eruption was from Mount Pinatubo in June 1991 from Philippines. The use of small balloons permitted us to reduce significantly the campaign costs along with an easy access to launching facilities in different parts of the world. The SRS project demonstrated the complete success of such a kind of observation strategy.

A quite wide amount of data on the status of the stratosphere was taken during the years 1996-1997. The different instruments provided measurements on several stratospheric gases like $\mathrm{O}_{3}, \mathrm{H}_{2} \mathrm{O}, \mathrm{N}_{2} \mathrm{O}, \mathrm{CFCs}, \mathrm{CH}_{4}$, $\mathrm{NO}_{2}, \mathrm{OClO}, \mathrm{BrO}$. They also sampled particles like background aerosols and PSCs, pressure and temperature at different latitudes and from the tropopause up to $30 \mathrm{~km}$. During this project a laser backscattersonde (LABS) was operated giving measurements of background aerosol and polar stratospheric clouds. The most interesting observations were made in the arctic, on polar stratospheric clouds, and in the tropics.

At least two of the polar stratospheric clouds resulted in quite interesting case studies. The PSC observed on 23 January, 1996, was simultaneously observed by two groundbased lidars and in situ by OPC-LABS. This is the first measurement of the refractive index in the visible range of wavelengths of the liquid ternary solution particles. A refractive index of 1.47 at $692 \mathrm{~nm}$ was measured by the combination of OPC and LABS data. Such a cloud was observed on the external side of the polar vortex edge. The other PSC, observed in the same year on 6 February, appears to be a clear example of clouds formed of SAT particles generated out of a gravity wave perturbation consequent to a cyclonic circulation above south Greenland. This case is still under study.

Both arctic and mid-latitude measurements of background aerosols gave backscattering ratios of 1.2 at $692 \mathrm{~nm}$ during 1996. It was observed that the background aerosol layer extended up to $25 \mathrm{~km}$ over France and even higher over central America where the tropopause was split into two distinct levels at 14.8 and $16 \mathrm{~km}$. Consequently the aerosol background layer was observed extending above $30 \mathrm{~km}$.

In the tropics, quite stratified aerosol layers were observed in the lower stratosphere between 20 an $30 \mathrm{~km}$. The stratification suggests the presence of relatively young aerosols recently injected into the stratosphere possibly by a deep convective system. More systematic observation would be needed in the future for a better characterization of the aerosol budget in the intertropical regions.

Acknowledgements. Topical Editor F. Vial thanks U.P. Hoppe and another referee for their help in evaluating this paper.

\section{References}

Adriani, A., F. Cairo, M. Viterbini, S. Mandolini, and G. Di Donfrancesco, Multiwavelength aerosol scatterometer for airborne experiments to study the optical properties of the stratospheric aerosol, J. Atmos. Ocean. Tech., (in press), 1999.
Adriani, A., F. Cairo, S. Mandolini, G. Di Donfrancesco, T. Deshler, and B. Nardi, A new joint balloon-borne experiment to study polar stratospheric clouds: laser backscatter sonde and optical particle counter, in Eds. R.D. Bojkov, and G. Visconti, Atmospheric Ozone, Proceedings of XVIII Quadriennial Ozone Symposium, vol 2, 879-882, Edigrafital for Parco Scientifico e Tecnologico d'Abruzzo, 1998.

Browell, E. V., C. F. Butler, S. Ismail, P. A. Robinette, A. F. Carter, N. S. Higdon, O. B. Toon, M. R. Schoeberl, and A. F. Tuck, Airborne lidar observations of nitric acid aerosol formation in the wintertime Arctic stratosphere: 1, polar stratospheric clouds, Geophys. Res. Lett., 17, 385-388, 1990.

Carslaw, K. S., B. Luo, and Te. Peter, An analytic expression for the composition of acqueous $\mathrm{HNO}_{3}-\mathrm{H}_{2} \mathrm{SO}_{4}$ stratospheric aerosolincluding gas phase removal of $\mathrm{HNO}_{3}$, Geophys. Res. Lett., 22, 1877-1880, 1995.

Cohen, A. J., and W. Low, An experimental determination of the depolarization of scattered laser light by atmospheric air, J. Appl. Meteorol., 8, 952-954, 1969.

Collis, R. T. H., and P. B. Russel, Lidar measurements of particles and gases by elastic backscattering and differential absorption, in Laser Monitoring of the Atmosphere, Ed. E.D. Hinkley, Topics in Applied Physics, Springer-Verlag, Berlin Heidelberg New york 1976.

Danis, F., K. Persson, H. Nilsson, A. D. Robinson, M. P. Chipperfield, J. D. McIntyre, P. G. Simmonds, N. R. P. Harris, and J. Pyle, Tracer measurements with DESCARTES during ILAS in early 1997, Proc. of $4^{\text {th }}$ European Symposium on Polar Stratospheric Ozone Research, Schlierzee, Bavaria, Sept. 1997, EC Air pollution research report 66, 423-426, 1998.

Deniel, C., R. M. Bevilacqua, F. Lefevre, and J. P. Pommereau, Measued and simulated ozone ozone loss in the arctic polar vortex in 1996, Geophys. Res. Lett., (in press), 1998.

Deshler, T., B. J. Johnson, and W. R. Rozier, Changes in the character of polar stratospheric clouds over Antarctica in 1992 due to the Pinatubo volcanic aerosol, Geophys. Res. Lett., 21, 273-276, 1994.

Deshler, T., B. Nardi, A. Adriani, F. Cairo, G. Hansen, and F. Fierli, The characterization of polar stratospheric clouds above Scandinavia by combining in situ measurements and lidar, $O n$ polar stratospheric ozone 1997, Proc. of the IV European Symposium, Eds. N.R.P. Harris I. Kilbane-Dawe G.T. Amanatidis, EUR 18032, 1998.

Deshler, T., B. Nardi, A. Adriani, F. Cairo, G. Hansen, and F. Fierli, Determining the index of refraction of polar stratospheric clouds above Andoya $\left(69^{\circ} \mathrm{N}\right)$ by combining size resolved concentration and optical scattering measurements, J. Geophys. Res., in press, 1999

Fierli, F., F. Cairo, L. Pulvirenti, B. Nardi, S. Mandolini, G. Di Donfrancesco, A. Adriani, A. Hauchecorne, F. Goutail, A. Sarkissian, T. Deshler, V. Rizi, G. Redaelli, G. Visconti, and B. Knudsen, Jan 23rd 1996 PSC above Andoya: different aerosol characteristics retrieval from backscatter data, comparison with optical particle counter measurements and interpretation by Lagrangian box modelling, On polar stratospheric ozone 1997: Proc. of the IV European Symposium, Eds. N.R.P. Harris I. Kilbane-Dawe G.T. Amanatidis, EUR 18032, 1998.

Gobbi, G. P., and A. Adriani, Mechanisms of formation of stratospheric clouds observed during the Antarctic late winter of 1992, Geophys. Res. Lett., 20, 1427-1430, 1993.

Hanson, D. R., and K. Mauersberger, Laboratory studies of the nitric acid trihydrate: implication for the south polar stratosphere, Geophys. Res. Lett., 15, 855-858, 1988.

Hofmann, D. J., and T. Deshler, Stratospheric cloud observations during formation of the Antarctic ozone hole in 1989, J. Geophys. Res., 96, 2897-2912, 1991.

Jaeger, H., and D. Hofmann, Midlatitude lidar backscatter to mass, area, and extintion conversion model based on in situ aerosol measurements, Appl. Opt., 30, 127-138, 1991. 
Jaeger, H., T. Deshler, and D. Hofmann, Midlatitude Lidar backscatter conversion model based on ballon-borne aerosol measurements, Geophys. Res. Lett., 22, 13, 1729-1732, 1995.

Khattatov, V., V. Yushkov, I. Zaitzev, M. Khaplanov, J. Rosen, and N. Kjome, Some results of water vapor, ozone and aerosol balloon borne measurements during EASOE., Geophys. Res. Lett., 21, 13, 1299-1302, 1994.

Larsen, N., J. M. Rosen, N.T. Kjome, and B. Knudsen, Deliquiscence and freezing of stratospheric aerosol observed by balloon-borne backscattersonde, Geophys. Res. Lett., 22, 12331236, 1995.

Lambert, J-C., M. Van Roozendael, M. De Maziere, P. C. Simon, J-P. Pommereau, F. Goutail, A. Sarkissian, and J. F. Gleason, Investigation of to pole - to pole performances of space-borne atmospheric chemistry sensors with the NDSC, J. Atmos. Sci., 56, 176-193, 1999.

Nilsson, H., K. Persson, F. Danis, N. Harris, and J. Pyle, CFC measurements with DESCARTES during the ILAS validation campaign - early results, Proc. $13^{\text {th }}$ ESA Symposium on Rocket and Balloon Programmes and Related Research, ESA SP-397, 231-236, 1997.

Peter, T., Microphysics and heterogeneous chemistry of polar stratospheric clouds, Ann. Rev. Phys., 48, 779-816, 1997.
Pommereau, J. P., F. Goutail, J. Piquard, L. Denis, and C. Phillips, The SAOZ balloon optical sonde for atmospheric chemistry study, Proc. 11th ESA Symp. Eur. Rocket and Balloon Prog., ESA SP 355, 87, 1994.

Pommereau, J. P., J. A. Pyle, and R. Zellner, Stratospheric chemistry, in European Research in the Stratosphere, Chap. 4, Stratospheric Chemistry, Ed. European Commission, Report EUR 16986 EN, 1998.

Preston, K. E., R. L. Jones, and H. K. Roscoe, Retreival of $\mathrm{NO}_{2}$ vertical profiles from ground-based UV-visible measurements: method and validation, J. Geophys. Res., 102, 19089-19097, 1997.

Pundt, I., J. P. Pommereau, C. Phillips, and E. Lateltin, Upper limit of iodine oxide in the lower stratosphere, J. Atmos. Chem., 30, 173-185, 1998.

Pyle, J. A., G. D. Carver, and U. Schmidt, Some case studies of chlorine activation during the EASOE campaign, Geophys. Res. Lett., 21, 1431-1434, 1994.

Toon, O., E. Browell, B. Gary, L. Lait, J. Livingston, P. Newman, R. Pueschel, P. Russel, M. Schoeberl, G. Toon, W. Traub, F. P. J. Valero, H. Selkirk, and J. Jordan, Heterogeneous reaction probabilities, solubilities, and the physical state of cold volcanic aerosols, Science, 261, 1136-1140, 1993.

Young, A. T., Revised depolarization correction for atmospheric extinction, Appl. Opt., 19, 3427-3428, 1980. 